\title{
INDICADORES REPRODUTIVOS DAS ESPÉCIES DE CITHARICHTHYS BLEEKER (TELEOSTEI, PLEURONECTIFORMES) NA BAÍA DE GUARATUBA, PARANÁ, BRASIL ${ }^{1}$
}

\author{
Paulo de Tarso C. Chaves ${ }^{2}$ \\ Ana Lúcia Vendel ${ }^{3}$
}

\begin{abstract}
REPRODUCTIVE INDICES FROM SPECIES OF CITHARIHTHYS BLEEKER (TELEostei, Pleuronectiformes) at the Guaratuba Bay, Paraná, Brazil. The species of Citharichthys Bleeker, 1862, C. arenaceus Evermann \& Marsh, 1900 and C. spilopterus Günther, 1862, are the most common flatfishes found in Guaratuba Bay, south Brazil. Different size categories of these flatfish occur in the mangrove area throughout the year. The Gonadosomatic Index, the Condition Factor, and the morphological analyses of the gonads from samples obtained between 1994 and 1996 reveals a spawning activity during late Spring and early Summer. This period coincides with the increase in temperature and decrease in salinity. Spawning evidence and the presence of all size categories throughout the year indicate that Citharichthys spp. are permanent inhabitants of the mangrove in Guaratuba Bay, where they complete their life cycle.

KEY WORDS. Teleostei, Pleuronectiformes, fish reproduction, Guaratuba Bay, Brazil
\end{abstract}

Assim como outros Pleuronectiformes, Citharichthys arenaceus Evermann \& Marsh, 1900 e C. spilopterus Günther, 1862 (Bothidae) apresentam uma larga distribuição no litoral brasileiro. São comuns também no litoral paranaense, onde, por seu porte reduzido, não apresentam utilização habitual para o consumo humano. Na Baía de Guaratuba, observações resultantes de 2,5 anos de levantamento ictiofaunístico indicam que essas são as espécies de linguado mais abundantes na área de manguezal, uma região de fundo lodoso e fortemente submetida a oscilações de temperatura e salinidade, onde predominam em diversidade e abundância os Sciaenidae, Gerreidae, Ariidae e Tetraodontiformes. Outros Pleuronectiformes simpátricos são Etropus crossotus (Jordan \& Gilbert, 1882), Symphurus plagusia (Bloch \& Schneider, 1801) e Achirus lineatus (Linnaeus, 1758), porém superados em número e biomassa por Citharichthys spp., que ocorrem de forma constante em todas as estações do ano. A hipótese de que os linguados dessas duas espécies possuem populações permanentes no interior da Baía de Guaratuba representa um significativo subsídio à avaliação do papel deste sistema para as comunidades

1) Contribuição número 959 do Departamento de Zoologia, Universidade Federal do Paraná.

2) Departamento de Zoologia, Universidade Federal do Paraná. Caixa Postal 19020, 81531-990 Curitiba, Paraná, Brasil. Bolsista do CNPq.

3) Bolsista PIBIC/CNPq/UFPR. 
ictíicas litorâneas, e tal idéia pode ser reforçada se for demonstrado que eles desovam na região. Assim, este trabalho reúne métodos qualitativos e quantitativos com o objetivo de avaliar se esses linguados efetivamente completam sua reprodução no interior da Baía de Guaratuba. Os resultados obtidos são a seguir apresentados e discutidos.

\section{MATERIAL E MÉTODOS}

Foram analisados 495 exemplares de $C$. arenaceus e $C$. spilopterus, coletados mensalmente entre janeiro de 1994 e junho de 1996, através de arrasto de fundo

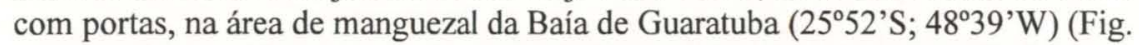
1). Nos últimos 12 meses, tomaram-se dados de temperatura e salinidade da água, com auxílio de garrafa tipo Van Dorn para acesso à água de fundo. Após a coleta, os exemplares foram transportados sob resfriamento para análise laboratorial, que incluiu biometria em todos os indivíduos (peso e comprimento total), e reconhecimento do sexo e avaliação do estágio de maturação - bem como pesagem das gônadas - em parte deles. Os ovários de 15 indivíduos foram examinados também microscopicamente, através de procedimentos histológicos de rotina, conforme citado em CHAVES (1995).

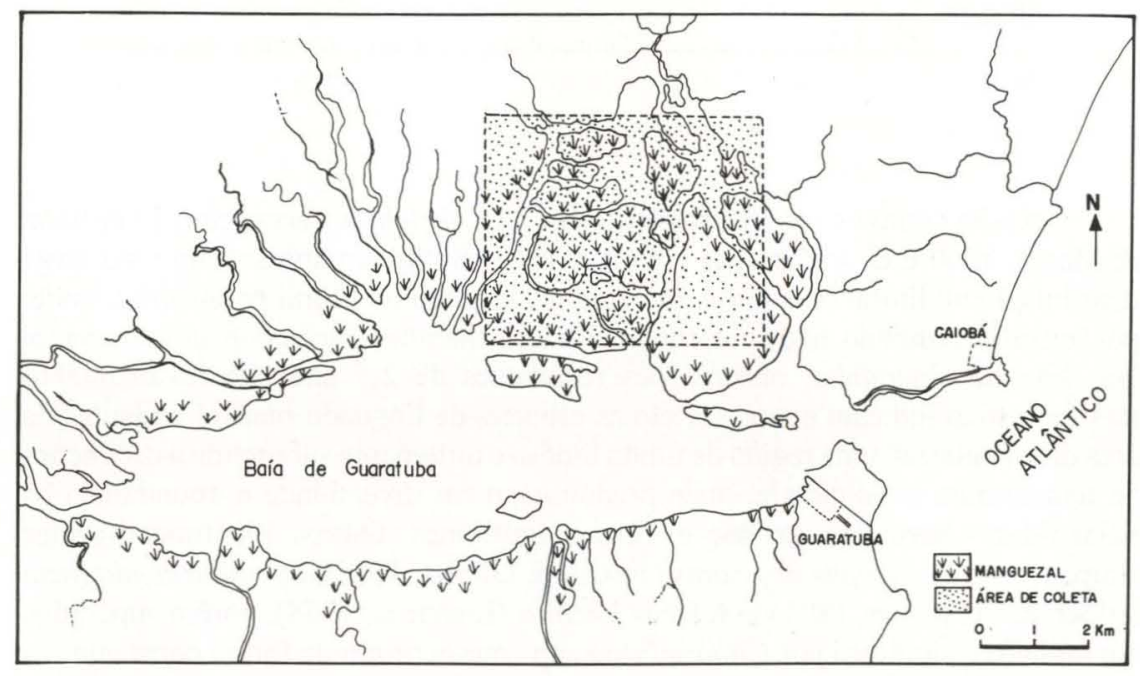

Fig. 1. Localização da área de estudo (retângulo pontilhado) dentro da Baía de Guaratuba, litoral do Paraná, Brasil (2552'S, 48³9'W).

A análise dos dados considerou, para sexos grupados, a variação mensal do Fator de Condição Total, calculado segundo VAZzOLER (1996), utilizando o coeficiente angular da regressão logaritimizada da relação Peso/Comprimento. Também foi considerada, apenas para fêmeas, a variação mensal da Relação Gonadossomá- 
tica no período 95/96 (RGS = Peso das gônadas/Peso total X 100). Finalmente, analisou-se a freqüência sazonal de fêmeas em reprodução, que foram definidas como aquelas onde havia gônadas hidratadas ou eliminando ovócitos sob pressão manual, ou ainda que histologicamente apresentavam indicadores histológicos de desova recente, tais como folículos vazios (= pós-ovulatórios) ou processos cicatriciais de recuperação. Para delimitação do período correspondente a cada estação do ano, observou-se o fato de as coletas terem sido realizadas sempre na primeira quinzena de cada mês. Portanto, janeiro, fevereiro e março compuseram o verão, e assim sucessivamente.

\section{RESULTADOS}

A figura 2 apresenta os valores mensais médios de temperatura e salinidade de fundo na região de coleta. A profundidade local variou entre dois e seis metros.

Os exemplares coletados situaram-se entre 60 e $190 \mathrm{~mm}$ de comprimento total, sem expressiva variação da média ao longo do ano - esta variou entre 104,8 e 126,1 mm (Fig. 3). A relação peso/comprimento dos dados empíricos manifestou tendência exponencial (Fig. 4). Logaritimizados os valores de peso (PT) e de comprimento (CT), a regressão linear obtida foi: $\ln \mathrm{PT}=-12,1292+3,0941 \ln \mathrm{CT}$ $(r=0,9713)$.

A variação mensal do Fator de Condição, utilizando o valor 3,0941 como expoente do comprimento, está representada na figura 5. Verificam-se decréscimos em outubro e em maio, mas a menor média foi registrada em novembro. O maior valor foi alcançado no meio do verão, em fevereiro.

Quanto à Relação Gonadossomática, teve suas maiores médias entre o final da primavera e meados do verão, sobretudo em dezembro e fevereiro. As menores médias foram registradas em junho e em setembro (Fig. 6).

A análise morfológica de gônadas, por sua vez, evidenciou que indivíduos em atividade reprodutiva foram mais freqüentes nos meses de primavera e verão que em outros (Fig. 7). Tal atividade pôde ser detectada especialmente pela visualização macroscópica de ovócitos hidratados, pela liberação de ovócitos mediante pressão manual na cavidade abdominal, e ainda pela detecção de folículos vazios, pós-ovulatórios, em preparações histológicas de exemplares coletados nos meses de outubro, novembro, dezembro, fevereiro e março.

\section{DISCUSSÃO}

Os altos valores de salinidade observados na maior parte do ano, seguidos de substancial decréscimo em meses de verão, bem caracterizam a área transicional continente-oceano em que se situa a região estudada. Variação sazonal como esta, diretamente influenciada por chuvas na bacia de drenagem, foi registrada por BRANDINI \& THAMM (1994) na Baía de Paranaguá, distante 30 quilômetros da Baía de Guaratuba. A temperatura da água, por sua vez, acompanhou as tendências atmosféricas normais para cada estação, conseqüência também da profundidade relativamente pequena nos pontos de coleta. 
VARIAÇÃO MENSAL MÉDIA DE TEMPERATURA E SALINIDADE DE FUNDO

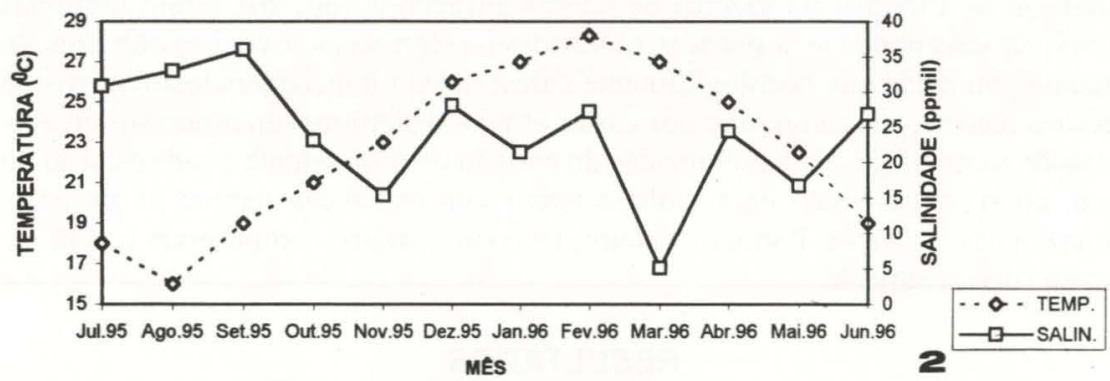

\section{COMPRIMENTO DOS EXEMPLARES COLETADOS}

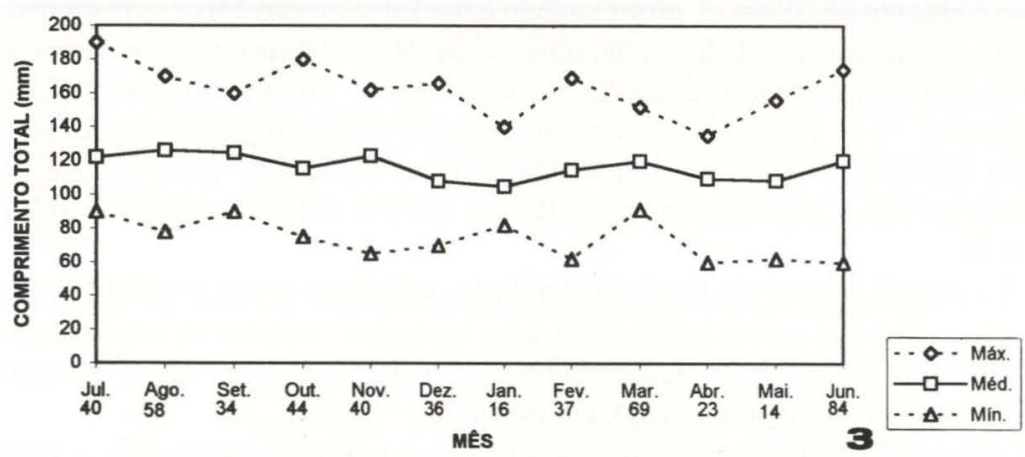

RELAÇÃO PESO/COMPRIMENTO

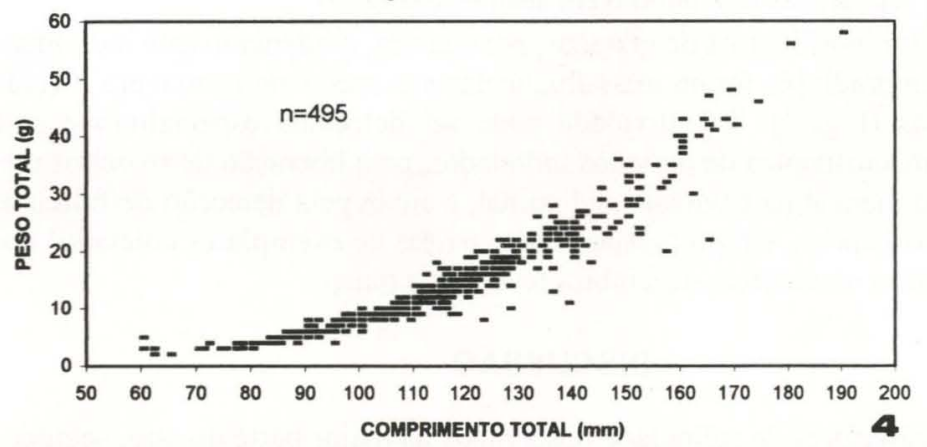

Figs 2-4. (2) Valores de temperatura e salinidade da água de fundo na região de estudo (médias entre os pontos de amostragem, no horário de coleta). Período de referência: julho de 1995 a junho de 1996; (3) amplitude de comprimento dos exemplares estudados de Citharichthys spp., sexos grupados, bem como tamanho médio, segundo o mês de coleta. Periodo de referência: janeiro de 1994 a junho de 1996. Abaixo de cada mês é indicado o tamanho da amostra; (4) pontos empíricos indicando peso e comprimento dos exemplares analisados de Citharichthys spp., sexos grupados, no periodo janeiro de 1994 a junho de 1996. 


\section{VARIAÇÃO MENSAL DO FATOR DE CONDIÇÃO}
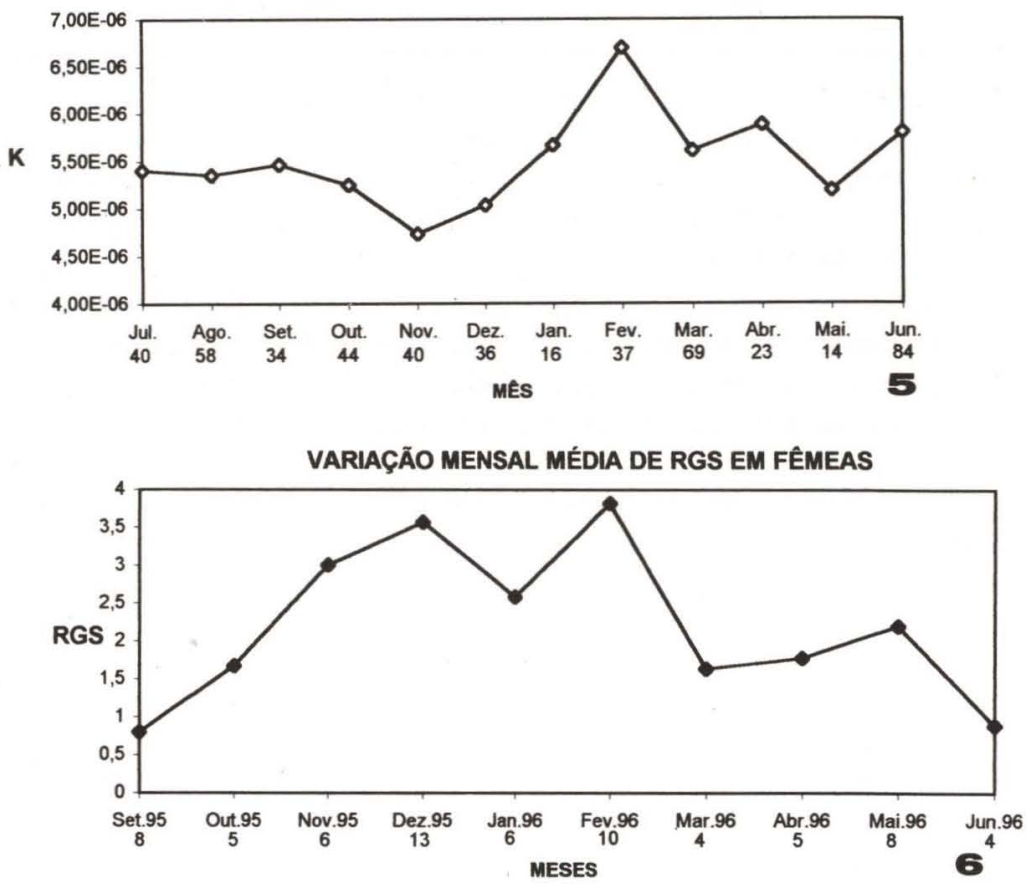

FREQÜÊNCIA SAZONAL MÉDIA DE INDIVÍDUOS EM REPRODUÇÃO

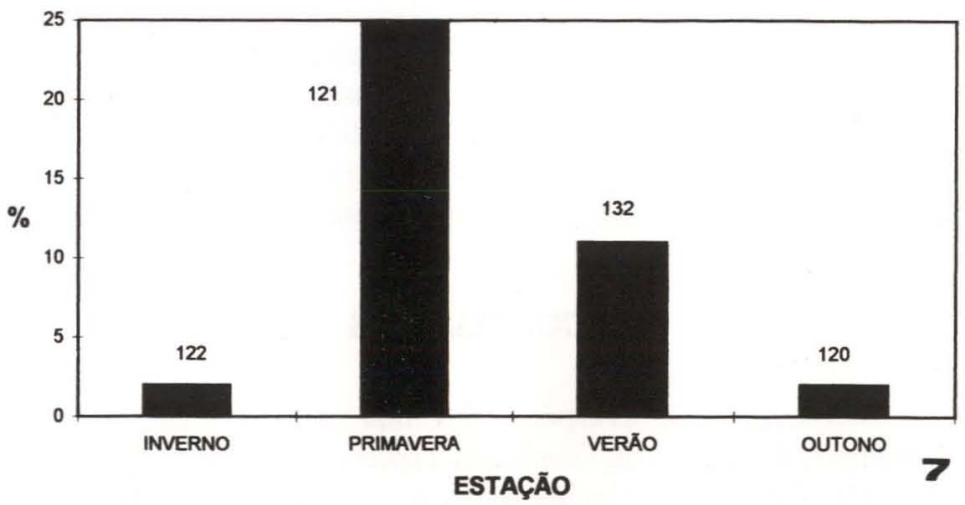

Figs 5-7. (5) Valores médios do Fator de Condição Total em Citharichthys spp., sexos grupados, segundo o mês de coleta, no periodo janeiro de 1994 a junho de 1996 (abaixo de cada mês é indicado o tamanho da amostra); (6) valores médios da Relação Gonadossomática de fêmeas de Citharichthys spp., segundo o mês de coleta, no periodo setembro de 1995 a junho de 1996 (abaixo de cada mês indica-se o número de exemplares analisados quanto a esta variável); (7) Freqüência relativa de indivíduos de Citharichthys spp. em reprodução, segundo a estação do ano, no período janeiro de 1994 a junho de 1996 (acima de cada coluna indica-se o número total de exemplares analisados). 
A análise morfológica das gônadas, tanto macroscópica quanto histológica, evidenciou que as espécies de Citharichthys efetivamente desovam no interior da Baía de Guaratuba. Às épocas de maior freqüência de indivíduos em atividade reprodutiva (primavera e verão) correspondem médias mensais também mais elevadas na Relação Gonadossomática, sobretudo em dezembro e fevereiro. Pela conjugação destes dois indicadores, estima-se que parte dos indivíduos começa a desovar na região ainda durante a primavera, mas que o processo adquire sua maior intensidade no início do verão.

A análise da relação peso-comprimento, cujo valor do coeficiente angular revelou-se próximo a 3,00, indica que o crescimento de $C$. arenaceus e $C$. spilopterus na região e faixa de tamanho estudadas é do tipo isométrico. O Fator de Condição médio das amostras $(\mathrm{K})$ apresentou nítida variação mensal. Sabe-se que este parâmetro pode alcançar valores mais elevados na época que antecede a desova de uma espécie, visto o acúmulo de reservas energéticas para o período reprodutivo (VAZZOLER 1996). Durante a estação de desova, os valores de K costumam sofrer redução, tanto pela diminuição no peso das gônadas, como pelo consumo das reservas somáticas do indivíduo, fato já descrito para diversos teleósteos (ANDRIAN \& BARBIERI 1992). Portanto, a redução nos valores de K, verificada durante a primavera, é mais um indicador de que nesta época ocorre desova das espécies de Citharichthys na região. Quanto à forte ascenção observada em janeiro e fevereiro, e que foi seguida de declínio entre março e maio, pode ser conseqüência ou da desova em si (VAZZOLER 1996), ou de mudança nas condições alimentares dos indivíduos, pois o Fator de Condição também está sujeito a tal tipo de influência (ANDRIAN \& BARBIERI 1992). De fato, em um outro Bothidae do litoral do Rio de Janeiro (Etropus longimanus Norman, 1933), SAAD \& FAGUNDES-NETO (1992) verificaram que a desova está estreitamente relacionada ao aumento na concentração de nutrientes na massa d'água. É possível, então, que em $C$. arenaceus e $C$. spilopterus algo semelhante aconteça: a desova antecederia exatamente a época de maior temperatura na região, quando a disponibilidade alimentar na Baía de Guaratuba e/ou o desempenho metabólico e a atividade trófica dos indivíduos é presumivelmente maior, aumentando assim as chances de sobrevivência das larvas.

\section{CONCLUSÕES}

Conclui-se, pois, que as espécies de Citharichthys efetivamente desovam na área de manguezal da Baía de Guaratuba, especialmente ao final de primavera e início de verão. Esta época coincide com a ascenção da temperatura da água, bem como com a ocorrência de valores mais baixos de salinidade que aqueles verificados no inverno. Semelhante comportamento foi registrado para o Sciaenidae Bairdiella ronchus (Cuvier, 1830) (CHAVES 1995), e talvez esteja associado às condições abióticas ideais para os jovens no meio do verão. Porém, ao contrário do observado para $B$. ronchus, é provável que $C$. arenaceus e $C$. spilopterus sejam moradores permanentes da área de manguezal, utilizando este ambiente tanto como área de reprodução quanto de crescimento. 
AGRADECIMENTOS. Aos colegas Gastão C.C. Bastos, do Instituto de Pesca do Estado de São Paulo, e Marco Fábio Maia Corrêa, Walter A. Boeger, Adriana Portes Santos e Adriana Serenato (Universidade Federal do Paraná), pela colaboração prestada em diversas etapas do trabalho. Ainda a dois Revisores anônimos.

\section{REFERÊNCIAS BIBLIOGRÁFICAS}

ANDRIAN, I.F. \& G. BARBIERI. 1992. Relação peso total/comprimento total e fator de condição do cangati, Parauchenipterus galeatus Linnaeus, 1766 (Siluriformes, Auchenipteridae) da região do Reservatório de Itaipu, PR. Unimar, Maringá, 14 (supl.): 163-176.

BRANDINI, F.P. \& C.A.C. ThAmM. 1994. Variações diárias e sazonais do fitoplâncton e parâmetros ambientais na Baía de Paranaguá. Neritica 8 (1/2): 55-72.

Chaves, P.T.C. 1994. A incubação de ovos e larvas em Genidens genidens (Valenciennes) (Siluriformes, Ariidae) da Baía de Guaratuba, Paraná, Brasil. Revta bras. Zool. 11 (4): 641-648.

. 1995. Atividade reprodutiva de Bairdiella ronchus (Cuvier) (Pisces, Sciaenidae) na Baía de Guaratuba, Paraná, Brasil. Revta bras. Zool. 12 (4): 759-766.

SAAD, A.M. \& E. FAGUNDES-NETTO. 1992. Aspectos da biologia reprodutiva de fêmeas de Etropus longimanus Norman, 1933 (Bothidae) da região de Cabo Frio, Rio de Janeiro. 1. Tamanho da primeira maturação, tipo e época de desova. Bolm. Inst. oceanogr., S Paulo, 40 (1/2): 1-13.

Vazzoler, A.E.A. DE M. 1996. Biologia da Reprodução de Peixes Teleósteos: Teoria e Prática. Maringá, EDUEM/SBI, 169p.

Recebido em 26.IX.1996; aceito em 13.II.1997. 